\title{
STUDY OF CLINICO ELECTROPHYSIOLOGICAL PROFILE OF DIABETIC NEUROPATHY
}

Sachin. G. J, Ravi Vaswani, Shilpa. B.

1. Assistant Professor, Department of Medicine, Vijayanagara Institute of Medical Sciences. Bellary.

2. Professor, Department of Medicine, Vijayanagara Institute of Medical Sciences. Bellary.

3. PG Student, Department of Pathology, MRMC, Gulbarga.

\section{CORRESPONDING AUTHOR}

Sachin G. J.

\# 17 pg boys hostel,

Vims opd campus,

Bellary

E-mail: sachingj80@gmail.com

Ph: 00919880048587.

ABSTRACT: BACKGROUND: Diabetic neuropathy is a common and troublesome microvascular complication of diabetes. It includes wide range of abnormalities involving peripheral and autonomic nerve functions. The aim of this study was to clinically evaluate various neuropathies in diabetic patients and to assess the relationship between duration of diabetes and onset of neuropathy and coexistence of peripheral neuropathy and autonomic neuropathy. METHOD: Subjects ( $n=50$, mean age-57.6 years) with diabetes were studied. Evaluation of peripheral neuropathy was based on clinical symptoms, signs and nerve conduction study. Assessment of autonomic neuropathy was based on a battery of Ewing's cardiovascular autonomic tests. RESULTS: Diabetic polyneuropathy (76\%) was the most common neuropathy detected. Numbness $(80.3 \%)$ was the most common symptom with decreased sense of vibration $(81.5 \%)$ being the most common sign. Loss of ankle jerk was seen in $65.7 \%$. Autonomic neuropathy was detected in $26 \%$. Neuropathy was more common in 5th decade of life with male preponderance. Association between disease duration and risk of diabetic neuropathy is strong. CONCLUSION: Distal symmetric polyneuropathy and autonomic neuropathy were the commonest types of neuropathy in diabetes mellitus. We suggest that all the patients with diabetes should undergo the common tests for autonomic dysfunction. The association of duration of diabetes and neuropathy was strong. Coexistence of autonomic and peripheral neuropathies was also observed.

KEY WORDS: Autonomic neuropathy, peripheral neuropathy, diabetes mellitus, diabetic poly neuropathy.

INTRODUCTION: Diabetes mellitus is a chronic metabolic disorder characterized by chronic hyperglycemia and organ dysfunctions due to alterations in the micro or macrovascular circulation. Neuropathy is a common troublesome microvascular complication. Diabetic neuropathy covers a wide range of abnormalities involving peripheral, cranial and autonomic nerve with varying clinical manifestations, anatomic distributions, courses and pathophysiologies. It being not always dependent on duration of diabetes and recently diagnosed diabetics have been reported to have neuropathy.

Uncertainty exists regarding prevalence of neuropathy in diabetics, even though it being one of the earliest, most common and most troublesome complications. The prevalence of 
diabetic neuropathy varies widely from $10-90 \%$ depending on the criteria and methods used to define neuropathy . $^{1-3}$

The early recognition and management of neuropathy is important because diabetic peripheral neuropathy can be asymptomatic and patients with such insensate feet are prone to injury. Diabetic autonomic neuropathy causes substantial morbidity and increased mortality, particularly if cardiovascular impairment is present. Electrophysiological assessment of nerve function by nerve conduction studies is a very sensitive and specific investigation, which can pick up impairement in asymptomatic patients also. In the background described above, this study was taken up to evaluate and study various types of neuropathies in diabetic patients admitted to the Yenepoya Medical Hospital.

AIMS OF THE STUDY: To study the clinicoelectrophysiological profile of neuropathy in diabetes mellitus. To study the prevalence of neuropathy in diabetes mellitus.

MATERIALS AND METHODS: Case Series Study conducted in department of medicine, Yenepoya Medical College Hospital, Deralakatte, Mangalore during October 2005 to October 2007, included 50 cases of DM with or without clinical evidence of neuropathy. Study was approved by ethical committee of the institution. Patients diagnosed to have Type 2 Diabetes mellitus according to ADA guidelines of age more than 18years of either sex were included. Diabetics with history of chronic Alcoholism, organophosphorous compound and lead exposure, pts with signs of Cerebrovascular accidents or Myelopathy, severe respiratory disease like COPD, thyrotoxicosis and drugs that alter autonomic nervous system tests were excluded. These patients were then subjected to bedside autonomic tests and nerve conduction study following detailed history and clinical examination. Median ulnar and peroneal nerves for motor conduction and median, ulnar and sural nerve for sensory conduction were conducted in all 4 limbs in all chosen diabetics.Ewing's battery of non invasive bedside cardiovascular tests were used for autonomic evaluation.

RESULTS \& DISCUSSION: Among 50 diabetics included in study 38 were diagnosed to have neuropathy on electrophysiological studies of which 35 were symptomatic and nerve conduction studies were abnormal in 3 asymptomatic patients. Advanced age turns out to be an independent risk factor for diabetic neuropathy ${ }^{4-5}$. Fedele and associates, in a multicenter study had $64 \%$ of patients with neuropathy in the age distribution of 50-59 years ${ }^{6}$, present study $27(71.01 \%)$ were of age above 50 years. The average age in the study was $57.6 y r s$ 7,8. In present study diabetic neuropathy was commonly observed in patients with duration of diabetes of more than 5 years $(47.3 \%$ with duration of $5-10$ years and $28.93 \%$ with duration > 10 years). The symptomatology study of diabetic neuropathy shows symptoms of distal polyneuropathy being commonest with either negative symptoms like tingling and numbness or positive painful symptoms ${ }^{9,10}$. In the present study tingling, numbness and burning sensation of feet and hands were the commonest symptoms. 28 patients (73.3\%) had numbness, 26 patients (66.7\%) had tingling, 19 patients (53.3\%) had burning sensation and 13 patients $(34.1 \%)$ presented with all symptoms. In the study done by Fedele and Associates the absence of ankle jerk (in $77.4 \%$ ) was the most common sign, the next common sign was impairment of vibration sense $^{6}$. In the present study after meticulous sensory system examination it was found that the most common sign was impairment or absence of vibration sense $(81.5 \%)$, the next common sign was impairment of touch sensation (70\%). However absence of ankle jerk was also found in significant number of patients $(65.7 \%)$. 
In the present study no patient had cranial nerve palsy or truncal neuropathy. Balachander and Chandrashekar observed autonomic symptoms in diabetes in order of frequency of postural giddiness(46\%) abnormal sweating(38\%) nocturnal diarrhea(38\%) gastric fullness $(20 \%)$ and hypoglycaemic unawareness(8\% ) ${ }^{11}$. In the present study incidence were as in table with postural giddiness being commonest. Gupta RC et al assessed patients with diabetic autonomic neuropathy and found abnormal blood pressure response to standing $(26 \%)$ and heart rate response to standing (56\%) while positivity of other tests ranged between $22-46 \% 12$. The results in present study of autonomic tests are as shown in Table 2, with incidence ranging from $4 \%$ to $26 \%$.

In the present study 38 Diabetic patients (60\%) were diagnosed to have distal polyneuropathy. Out of them $3(10 \%)$ were asymptomatic and diagnosed to have neuropathy on electrophysiological study. All 38 patients (100\%) had involvement of sensory fibres and 24 patients $(73.3 \%)$ had both sensory and motor involvement. Lomontagne and Buchtal ${ }^{13}$ did a study on 30 patients with distal polyneuropathy. 12 asymptomatics were found to have neuropathy. Concluding that nerve conduction study is useful in detecting sub-clinical forms of neuropathy. The most common type of neuropathy had been axonopathy, however some patients may be associated with demyelination according to Brown MJ et. al., and Behse F et. al.14,15 . In the present study 31 patients $(81.6 \%)$ had axonal degeneration alone and in 8 patients $(18.4 \%)$ there was associated segmental demyelination.

According to Tentolouris et al autonomic neuropathy and peripheral neuropathy do not invariably coexist. A coexistence of $45.35 \%$ was found in their study.In the present study coexistence of both autonomic neuropathy and peripheral was found in $20 \%$ of patients with type 2 diabetes.

CONCLUSION: Advancing age is an increased risk of diabetic neuropathy . The association between disease duration and the risk of diabetic neuropathy is strong and the same was reconfirmed in present study. The symptomatology of neuropathy varied and depend on the different types of neuropathy, with symptoms of distal symmetric polyneuropathy like tingling, numbness and burning sensation in a "glove and stocking" pattern of distribution being the commonest. Among the signs of neuropathy, impairment or absence of vibrations sense and absence of ankle jerks were common. Autonomic neuropathy incidence in diabetics is quite common with $40 \%$ having involvement in the present study. Abnormalities in the nerve conduction studies correlated to symptoms and signs of diabetic neuropathy. Sub-clinical neuropathy can be detected by nerve conduction studies. Coexistence of autonomic and peripheral neuropathy can occur in diabetics

\section{BIBLIOGRAPHY:}

1. Young MJ, Boultan AJM, Macleod AF. A multicentric study of the prevalence of diabetic neuropathy in United Kingdom hospital clinic population. Diabetologia . Oct 1996: 36: 1-5.

2. Caputo GM, Cavanagh PR, Ulbrecht JS. Assessment and management of foot disease in patients with diabetes. N Eng J Med 1989; 331: 854-860.

3. Dyck PJ, Kratz KM, Karnes JL et al. (1993)The prevalence by staged severity of various types of diabetic neuropathy, retinopathy and nephropathy in a population based cohort. The Rochester Diabetic Neuropathy Study. Neurology 43: 817-824.

4. Adler AI, Boyko EJ, Ahroni JH, Stensel V, Forsberg RC, Smith DG: Risk factors for diabetic peripheral sensory neuropathy : Results of the Seattle Prospective Diabetic Foot Study. Diabetes Care 20 : 1162-1167, 1997. 
5. Franklin GM, et al., Risk factors for distal symmetric neuropathy in NIDDM. The San Luis Vally Diabetes Study. Diabetes Care 1994;17 : 1172-1177.

6. Domeneco Fedele et al., A multicentre study on the prevalence of Diabetic Neuropathy in Italy In Diabetes Care. The journal of Clinical Applied Research and Education, May 1997; Vol 20, No. 5: 836-42.

7. Shaw JE, et al., Diabetic neuropathy in Mauritius. Prevalence and risk factors. Diabetes Res Clin Prack 1998; 42: 131-139.

8. Herman WH, et al., Diabetes mellitus in Egypt. Glycaemic control and microvascular and neuropathic complications. Diabetes Med.1998; 15: 1045-51.

9. Simon Eaton and Solomon Tesfaye. Clinical manifestations and measurement of somatic neuropathy. Diabetes Reviews. 1999; Vol 7. No 4: 312-14.

10. John D.Ward. Clinical aspects of diabetic somatic neuropathy. Chapter 62. In John Pickup and Gareth Williams (eds). Text book of Diabetes. London. Blackwell Scientific Publications. 1991; 624.

11. Balachander J, Chandrashekar S. autonomic neuropathy in diabetes mellitus, diabetes mellitus in developing countries. 1984; 285-289.

12. Jeyarajah $R$, samarawickrama et al. autonomic function tests in NIDDM patients and healthy volunteers. Journal of chronic diseases. 1986; 39; 479-84.

13. Lamontagne A Buchthal F. Electrlophysiological Studies in Diabetic Neuropathy J neurol Neurosurg psychiatry. 1970; 33: 4421.

14. Brown MJ, Asbury AK. Diabetic Neuropathy.Ann Neurol 1984;15: 2.

15. Behse F, Buchthal F, Carlsen F. Nerve Biopsy and conduction studies in Diabetic Neuropathy. J Neurol Neurosurg Psychiatry. 40: 1072.

TABLE 1: PREVALENCE OF DIABETIC NEUROPATHY WITH RESPECT TO VARIOUS PARAMETERS

\begin{tabular}{|l|l|l|}
\hline prevalence & $\begin{array}{r}\text { DN }- \\
\mathrm{n}=12\end{array}$ & $\begin{array}{c}\text { DN }+ \\
\mathrm{n}=38\end{array}$ \\
\hline AGE & & \\
\hline $40-49$ & 2 & 6 \\
\hline $50-59$ & 5 & 17 \\
\hline $60-69$ & 5 & 10 \\
\hline \multicolumn{1}{|c|}{$>70$ years } & 0 & 5 \\
\hline SEX & & \\
\hline Males & 5 & 24 \\
\hline Females & 7 & 14 \\
\hline Duration & & \\
\hline$<1$ year & 1 & 2 \\
\hline $1-5$ & 8 & 7 \\
\hline $5-10$ & 2 & 18 \\
\hline $10-15$ & 0 & 5 \\
\hline$>15$ years & 1 & 6 \\
\hline
\end{tabular}


TABLE 2: CLINICAL FEATURES OF PATIENTS WITH DIABETIC NEUROPATHY

\begin{tabular}{|l|l|l|}
\hline Symptoms & & \\
\hline Parasthesia & 26 & $68 \%$ \\
\hline Numbness & 28 & $73 \%$ \\
\hline Burning Sensation & 19 & $49 \%$ \\
\hline Pain worsening at night & 6 & $15 \%$ \\
\hline Weakness & 8 & $21 \%$ \\
\hline Ptosis Diplopia & 0 & $0 \%$ \\
\hline Giddiness & 22 & $44 \%$ \\
\hline Diarrhea alternating with constipation & 21 & $42 \%$ \\
\hline Excessive Sweating & 20 & $40 \%$ \\
\hline Erectile Dysfunction & 4 & $8 \%$ \\
\hline Signs & & \\
\hline Impairment or absence of & & \\
\hline vibration sense & 31 & 81 \\
\hline touch sensation & 27 & 71 \\
\hline position sense & 4 & 10 \\
\hline pain and temperature & 17 & 44 \\
\hline Abnormal autonomic tests & & \\
\hline Blood pressure response to standing & 13 & 26 \\
\hline Heart rate response to standing & 7 & 14 \\
\hline Blood pressure response to sustained hand grip & 12 & 24 \\
\hline Heart rate response to deep respiration & 2 & 4 \\
\hline Valsalva manoeuvre & 5 & 10 \\
\hline
\end{tabular}

TABLE 3: SIGNS IN POLY NEUROPATHY

\begin{tabular}{|l|l|}
\hline Signs of Diabetic Neuropathy & Present study \\
\hline vibration sense & $81.50 \%$ \\
\hline touch sensation & $71.00 \%$ \\
\hline Pain \& Temp & $44.70 \%$ \\
\hline ankle jerk & $65.70 \%$ \\
\hline
\end{tabular}

TABLE 4: NCV RESULTS

\begin{tabular}{|l|l|l|}
\hline Type of neuropathy & No of Pts & Percentage \\
\hline Only Axonal & 31 & $81.57 \%$ \\
\hline Both Axonal \& demyelination & 7 & $18.41 \%$ \\
\hline
\end{tabular}




\section{ORIGINAL ARTICLE}

TABLE 5: Association between autonomic neuropathy and pheripheral neuropathy

\begin{tabular}{|l|l|l|}
\hline & $\mathrm{PN}+$ & $\mathrm{PN}-$ \\
\hline $\mathrm{AN}+$ & 10 & 3 \\
\hline $\mathrm{AN}-$ & 28 & 9 \\
\hline
\end{tabular}

